\title{
Serum glutamine, set-shifting ability and anorexia nervosa
}

\author{
Michiko Nakazato*1,2, Kenji Hashimoto ${ }^{3}$, Ulrike Schmidt ${ }^{1}$, Kate Tchanturia', lain C Campbell1, David A Collier ${ }^{4}$, \\ Masaomi lyo 2,5 and Janet Treasure6
}

\begin{abstract}
Background: Set-shifting is impaired in people with anorexia nervosa (AN), but the underlying physiological and biochemical processes are unclear. Animal studies have established that glutamatergic pathways in the prefrontal cortex play an important role in set-shifting ability. However, it is not yet understood whether levels of serum glutamatergic amino acids are associated with set-shifting performance in humans. The aim of this study was to determine whether serum concentrations of amino acids related to glutamatergic neurotransmission (glutamine, glutamate, glycine, L-serine, D-serine) are associated with set-shifting ability in people with acute AN and those after recovery.

Methods: Serum concentrations of glutamatergic amino acids were measured in 27 women with current AN (AN group), 18 women recovered from AN (ANRec group) and 28 age-matched healthy controls (HC group). Set-shifting was measured using the Wisconsin Card Sorting Test (WCST) and the Trail Making Task (TMT). Dimensional measures of psychopathology were used, including the Eating Disorder Examination Questionnaire (EDEQ), the Maudsley Obsessive-Compulsive Inventory (MOCI) and the Hospital Anxiety and Depression Scale (HADS).

Results: Serum glutamine concentrations in the AN group $(1,310.2 \pm 265.6 \mu \mathrm{M}$, mean \pm SD) were significantly higher (by approximately $20 \%)$ than those in the $\mathrm{HC}$ group $(1,102.9 \pm 152.7 \mu \mathrm{M}$, mean $\pm \mathrm{SD})\left(F_{(2,70)}=6.3, P=0.003,95 \% \mathrm{Cl} 61.2\right.$ to 353.4). Concentrations of serum glutamine were positively associated with markers of the illness severity: a negative correlation was present between serum glutamine concentrations and body mass index (BMI) and lowest BMI and a positive correlation was found between duration of illness and EDEQ. The AN group showed significantly impaired set shifting in the WCST, both total errors, and perseverative errors. In the AN group, there were no correlations between serum glutamine concentrations and set shifting.

Conclusions: Serum concentrations of glutamine may be a biomarker of illness severity in people with AN. It does not appear to be directly associated with changes in executive function.
\end{abstract}

\section{Background}

Specific cognitive characteristics have been observed in people with eating disorders (ED) [1,2]. For example, setshifting difficulties have been found in people currently ill with anorexia nervosa (AN), in an attenuated form in people recovered from AN (ANRec) [3,4] and in unaffected sisters [5]. The problem has also been identified in bulimia nervosa $(\mathrm{BN})$, schizophrenia [6], bipolar disorder [7] and obsessive-compulsive disorder [8]. It appears to

\footnotetext{
* Correspondence: michiko.nakazato@nifty.ne.jp

1 Section of Eating Disorders, Institute of Psychiatry, King's College London, UK Full list of author information is available at the end of the article
}

be a trait as it is present in first-degree relatives of people with schizophrenia [9] and bipolar disorder [10].

Glutamate is the principal excitatory neurotransmitter in brain and is involved in cognitive functions such as memory and learning [11]. As glutamate concentrations in blood are correlated with those in cerebrospinal fluid (CSF) [12,13], serum levels may influence glutamatergic concentrations and functions in brain. This is of interest because muscle breakdown and gluconeogenesis during starvation is likely to increase serum glutamine. This proposal has some indirect support from proton magnetic resonance spectroscopy (MRS) studies, which have reported that people with AN have lower levels of a com- 
bined measure of glutamate and glutamine (Glx) and of $N$-acetyl aspartate (NAA) in the frontal grey matter [14]. Furthermore, executive functioning assessed using the Wisconsin Card Sorting Test (WCST) has been shown to be associated with Glx levels in the anterior cingulate gyrus (ACC) [15]. It has also been proposed that the agerelated decline in set-shifting ability is associated with alterations in glutamate receptor binding in the cingulate cortex and dorsomedial striatum [16]. These various studies suggest that the functioning of the glutamatergic system in the prefrontal region may be related to the impaired cognitive performance seen in people with AN and in other psychiatric disorders [17,18]. Animal studies support the idea that set shifting is associated with glutamatergic neurotransmission (for example, with $N$ methyl-D-aspartate (NMDA) receptor function) [16,19$21]$. MRS studies of people with AN [14,15,22,23] have shown heterogenous findings possibly due to methodological factors.

Based on the above findings, we hypothesised that, firstly, alterations in serum concentrations of glutamatergic amino acids (glutamate, glutamine, glycine, L-serine and D-serine) would be observed in individuals with AN and those with recovered AN and, secondly, that such alterations would be related to deficits in set-shifting ability in individuals with acute $\mathrm{AN}$ and those with recovered AN.

\section{Methods}

\section{Participants}

Of the 73 women who participated in this study, 27 had current AN (AN group), 18 had recovered from AN (ANRec group) and 28 were healthy age-matched controls (HC group) (Table 1). Individuals in the AN and ANRec groups were recruited from the South London and Maudsley National Health Service (NHS) Foundation Trust volunteer register of individuals with past or current ED. The HC group was recruited from volunteers in the local community.

All participants in the AN group met the American Psychological Society (APA) Diagnostic and Statistical Manual of Mental Disorders, fourth edition (DSM-IV) criteria [24] for AN (20 with the restrictive subtype, 7 with the binge-purge subtype). Seven patients were diagnosed with major depressive disorders; one also had an anxiety disorder and two had concurrent obsessive compulsive disorders. The ANRec group was defined according to the following criteria: (1) a history of AN of the restrictive subtype as defined by DSM-IV, (2) maintenance of a stable body mass index (BMI) between 18.5 and $24 \mathrm{~kg} / \mathrm{m}^{2}$ for a minimum of 1 year, (3) regular menstrual cycles (at least 10 cycles) during the past year, (4) binge eating and purging behaviours absent for 1 year, and (5) not having been prescribed any psychotropic medication during the past year. Inclusion criteria for the HC group were: (1) BMI between 19 and $26 \mathrm{~kg} / \mathrm{m}^{2}$, (2) no personal or family history of any psychiatric illness or ED, and (3) no current use of psychotropic medication. Groups were matched for age, ethnicity and educational level.

Exclusion criteria for all participants included a history of brain injury, psychosis, neurological or other severe medical illness, alcoholism or drug abuse/dependence. All participants had English as their first language. Ethical approval for the study was obtained from the Institute of Psychiatry and the South London and Maudsley NHS Trust Research Ethics Committee. All participants provided written informed consent for participation in the study.

\section{Clinical and self-report measures of psychopathology}

Current and lowest previous BMI was recorded for patients in the AN and ANRec groups. Neuropsychological assessments were carried out in all but three AN patients. Dimensional measures of psychopathology were used, including the Eating Disorder Examination Questionnaire (EDEQ) [25], which has four subscales of Restraint (EDEQ-R), Eating Concern (EDEQ-E), Weight Concern (EDEQ-W) and Shape Concern (EDEQ-S). The Maudsley Obsessive Compulsive Inventory (MOCI) [26] and the Hospital Anxiety and Depression Scale (HADS) [27] were used as dimensional measures to assess current anxiety, depression and obsessive-compulsive symptoms.

\section{Assay of serum glutamatergic amino acids}

Blood samples were drawn from all subjects by venepuncture in the morning (9:00 to 12:00). Approximately $10 \mathrm{ml}$ of peripheral venous blood was collected into additive-free containers and the samples were stored at $-80^{\circ} \mathrm{C}$ until needed.

Measurement of amino acids was carried out using methods described previously [18,28,29]. Serum levels of glutamate, glutamine, and glycine were measured using high performance liquid chromatography (HPLC) [28]. D-Serine and L-serine levels were determined by a column switching HPLC system with fluorescence detection [30]. A total of $20 \mu \mathrm{l}$ of the human serum was homogenised in $180 \mu \mathrm{l}$ of HPLC-grade methanol. Homogenates were then centrifuged at $4,500 \mathrm{~g}$ for $10 \mathrm{~min}$. Then, $20 \mu \mathrm{l}$ of supernatant was evaporated to dryness at $40^{\circ} \mathrm{C}$ and the residue was rehydrated by adding $20 \mu$ of $\mathrm{H}_{2} \mathrm{O}$ (HPLC grade), $20 \mu \mathrm{l}$ of $0.1 \mathrm{M}$ borate buffer ( $\mathrm{pH} 8.0$ ) and $60 \mu \mathrm{l}$ of $50 \mathrm{mM}$ 4-fluoro-7-nitro-2,1,3-benzoxadiazole (NBD-F; Tokyo Kasei Kogyo, Tokyo, Japan) in $\mathrm{CH}_{3} \mathrm{CN}$ (HPLC grade). The reaction mixture was then heated at $60^{\circ} \mathrm{C}$ for $1 \mathrm{~min}$, and immediately supplemented with $100 \mu \mathrm{l}$ of 
Table 1: Clinical characteristics and findings of serum amino acids (one-way ANOVA)

\begin{tabular}{|c|c|c|c|c|c|c|}
\hline & AN $(n=27)$ & ANRec $(n=18)$ & $H C(n=28)$ & $F$ & df & $P$ value \\
\hline Age, years & $27.7 \pm 10.6$ & $32.2 \pm 11.1$ & $26.9 \pm 5.8$ & 2.0 & 2,70 & 0.14 \\
\hline Education, years & $16.9 \pm 3.2$ & $17.0 \pm 2.8$ & $18.1 \pm 2.1$ & 1.5 & 2,66 & 0.23 \\
\hline Duration, years & $10.0 \pm 10.6$ & $6.6 \pm 6.2$ & NA & 13.7 & 2,69 & 0.00 \\
\hline Age of onset, years & $17.0 \pm 4.4$ & $18.4 \pm 6.4$ & NA & 152.7 & 2,69 & 0.00 \\
\hline Current BMI, kg/m² & $15.4 \pm 1.6^{a * * b * *}$ & $19.8 \pm 1.1^{b * * * * *}$ & $22.3 \pm 2.5$ & 85.6 & 2,68 & 0.00 \\
\hline Lowest BMI, kg/m² & $13.1 \pm 1.6^{\mathrm{a} * *}$ & $14.2 \pm 2.0^{c * *}$ & $21.0 \pm 2.4$ & 111.2 & 2,65 & 0.00 \\
\hline EDEQ R & $4.3 \pm 3.7^{a * * b * *}$ & $0.8 \pm 0.9^{b * *}$ & $0.6 \pm 1.0$ & 20.0 & 2,68 & 0.00 \\
\hline EDEQ E & $3.3 \pm 1.5^{a * * b * *}$ & $0.4 \pm 0.4^{\mathrm{b} * *}$ & $0.2 \pm 0.2$ & 86.9 & 2,68 & 0.00 \\
\hline EDEQ W & $4.1 \pm 1.7^{a * * b * *}$ & $1.0 \pm 0.9^{\mathrm{b} * *}$ & $0.5 \pm 0.6$ & 69.8 & 2,68 & 0.00 \\
\hline EDEQ $S$ & $4.6 \pm 1.6^{a * * b * *}$ & $1.5 \pm 0.9^{\mathrm{b} * *}$ & $0.9 \pm 0.7$ & 80.2 & 2,68 & 0.00 \\
\hline EDEQ G & $3.9 \pm 1.7^{a * * b * *}$ & $1.0 \pm 0.8^{\mathrm{b} * *}$ & $0.5 \pm 0.5$ & 65.7 & 2,67 & 0.00 \\
\hline $\mathrm{MOCl}$ & $10.1 \pm 6.0^{\mathrm{a} * *}$ & $8.7 \pm 4.2^{c^{* *}}$ & $3.7 \pm 2.8$ & 14.6 & 2,68 & 0.00 \\
\hline HADS anxiety & $14.0 \pm 4.4^{a * * b * *}$ & $8.7 \pm 2.8^{\mathrm{b} * * c * *}$ & $4.4 \pm 3.3$ & 45.9 & 2,66 & 0.00 \\
\hline HADS depression & $9.3 \pm 5.5^{\mathrm{a} * \mathrm{~b} * *}$ & $3.4 \pm 2.4^{\mathrm{b} * *}$ & $1.5 \pm 2.6$ & 28.7 & 2,66 & 0.00 \\
\hline Serum Glu, $\mu \mathrm{M}$ & $64.7 \pm 32.3$ & $45.0 \pm 29.6$ & $54.7 \pm 23.1$ & 2.7 & 2,70 & 0.08 \\
\hline Serum Gln, $\mu \mathrm{M}$ & $1,310.2 \pm 265.6^{a * *}$ & $1,159.0 \pm 236.3$ & $1,102.9 \pm 152.7$ & 6.3 & 2,70 & 0.00 \\
\hline Serum glycine, $M$ & $294.8 \pm 78.2$ & $280.9 \pm 82.9$ & $255.1 \pm 58.3$ & 2.1 & 2,70 & 0.13 \\
\hline Ratio of Glu/Gln & $0.064 \pm 0.065$ & $0.042 \pm 0.034$ & $0.052 \pm 0.025$ & 1.3 & 2,70 & 0.28 \\
\hline Serum $\mathrm{D}$-serine, $\mu \mathrm{M}$ & $2.2 \pm 0.8$ & $2.2 \pm 0.8$ & $1.9 \pm 0.5$ & 1.6 & 2,70 & 0.21 \\
\hline Serum L-serine, $\mu \mathrm{M}$ & $135.6 \pm 53.7$ & $158.4 \pm 72.7$ & $117.7 \pm 60.9$ & 2.4 & 2,70 & 0.10 \\
\hline
\end{tabular}

Values shown are mean $\pm \mathrm{SD} ;{ }^{*} P<0.05 ; * * P<0.01$.

aComparisons between $\mathrm{AN}$ and $\mathrm{HC} ;{ }^{\mathrm{b}}$ comparisons between $\mathrm{AN}$ and $\mathrm{ANRec} ;{ }^{\mathrm{c}} \mathrm{comparisons}$ between ANRec and $\mathrm{HC}$.

$\mathrm{AN}=$ anorexia nervosa; $\mathrm{ANOVA}=$ analysis of variance; $\mathrm{ANRec}=$ recovered from anorexia nervosa; $\mathrm{BMI}=$ body mass index; $\mathrm{df}=\mathrm{degrees}$ of freedom; EDEQ R = Eating Disorder Examination Questionnaire Restraint Subscale; EDEQ E = Eating Concern Subscale; EDEQ W = Weight Concern Subscale; EDEQ S = Shape Concern Subscale; EDEQ G = Global Scale; Glu = Glutamate; Gln = Glutamine; HADS = Hospital Anxiety and Depression Scale; HC $=$ healthy controls; $\mathrm{MOCl}=$ Maudsley Obsessive-Compulsive Inventory.

$\mathrm{H}_{2} \mathrm{O} / \mathrm{CH}_{3} \mathrm{CN}(90 / 10)$ containing $0.1 \%$ trifluoroacetic acid (TFA) to stop the reaction. A total of $10 \mu \mathrm{l}$ of the resultant solution was injected into the HPLC system $[28,29]$.

\section{Assessment of set-shifting ability}

The WCST [31] and the Trail Marking Task (TMT) [32] were used to assess executive function by the measurement of set-shifting ability.

The WCST involves matching stimulus cards with one of four category cards. The sorting rule (colour, shape or number) changes unpredictably after 10 correct sorts. The set-shifting outcome employed is the number of raw perseverative errors.

The TMT is a traditional set-shifting task. It requires participants to connect an alphabetical sequence on a page in a 'dot-to-dot' fashion (trail A), before alternatively linking numbers and letters in order (that is, 1-A-2-B-3-C (trail B)). A computerised version of the TMT was employed here [33]. The set-shifting outcome used was a balanced variable of trail B minus trail A, to control for baseline motor speed.

\section{Statistical analysis}

All data were analysed using SPSS V.17.0 for Windows (SPSS, Chicago, IL, USA). Results are presented as mean values \pm standard deviation (SD). Two-way analysis of variance (ANOVA) was carried out to test for the interaction between the groups of participants, cognitive impairment of set-shifting abilities and serological findings. One-way ANOVA was used to test for differences in clinical characteristics, neuropsychological tasks and serum amino acids concentrations between the groups. Where a significant overall difference between the groups was observed in ANOVA, pairwise comparisons were carried out using the Bonferroni-Dunn post hoc test to test the significance of different combinations of groups with respect to the outcome variables. Pearson's bivariate correlation coefficients were calculated to examine the 
relationship between serum concentrations of the different glutamatergic amino acids with clinical variables (age, education, duration of illness, current BMI, lowest BMI), and also with results from the neuropsychiatric dimensional tests (EDEQ subscale, MOCI and HADS anxiety and depression scores). The values of Cohen's $d$ were calculated to be $0.20,0.50$ and 0.80 (small, medium and large effect size, respectively), and $P$ values $<0.05$ were considered statistically significant.

\section{Results}

\section{Demographic and clinical characteristics}

Table 1 shows the demographic and clinical characteristics for all participants. There were no significant differences between the AN group and ANRec group in terms of current age, years of education, age of illness onset, duration of illness or lowest BMI. The ANRec group had been recovered for a mean duration of 7.2 years (SD 6.4; range 1 to 24). As expected, the AN group had a significantly lower BMI and a significantly higher level of psychopathology (as determined by the EDEQ and HADS anxiety and depression scores) than the ANRec and the HC groups. The effect sizes were calculated to be 1.16 for EDEQ-R, 1.56 for HADS anxiety and 1.38 for HADS depression scores. The ANRec group showed significantly higher levels of anxiety on MOCI and HADS anxiety testing compared with the $\mathrm{HC}$ group.

\section{Serum concentrations of amino acids}

Two-way ANOVA revealed no between-subjects effects of group or set shifting on serum concentration of amino acids.

Table 1 shows the concentrations of amino acids between the three groups. Serum glutamine concentrations in the AN group $(n=27)(1,310.2 \pm 265.6 \mu \mathrm{M}$, mean $\pm \mathrm{SD})$ were significantly higher than those in the $\mathrm{HC}$ group $(\mathrm{n}=28)(1,102.9 \pm 152.7 \mu \mathrm{M}$, mean $\pm \mathrm{SD})\left(F_{(2,70)}=\right.$ 6.3; $P=0.003$ ) (Figure 1). Table 2 shows the results of the post hoc Bonferroni-Dunn test for serum glutamine concentrations. Serum glutamine concentrations were significantly higher in the AN group than in the $\mathrm{HC}$ group $(P=$ $0.003 ; 95 \%$ CI 61.2 to 353.4 ). The effect size for the mean differences in serum glutamine was 0.87 , which is a large effect. There were no significant differences in the serum concentrations of the other amino acids (glutamate, glycine, D-serine and L-serine) between the three groups. The effect sizes for these were of a small and medium size: 0.36 for glutamate, 0.56 for glycine, 0.44 for $\mathrm{D}$-serine and 0.31 for L-serine, respectively.

\section{Neuropsychological findings}

Group comparisons for the neuropsychological tasks are presented in Table 3. The AN group showed significantly impaired set shifting on the WCST (both total errors and perseverative errors). The effect sizes were 0.71 for the total errors and 0.68 for perseverative errors. The scores for the ANRec group were between those of the AN group and the HC group, and this difference was not statistically significant.

\section{Correlations between serum glutamine concentrations, cognitive function and psychopathological features of EDs} In the sample that included the AN group and the ANRec group $(n=45)$, a negative correlation was found between serum glutamine concentrations and BMI $(P=0.026 ; r=-$ $0.339)$, and lowest BMI $(P=0.01 ; r=-0.386)$. A positive correlation was found between serum glutamine concentrations and HADS anxiety scores $(P=0.005 ; r=0.433)$. There were also positive correlations between serum glutamate concentrations and EDEQ-W scores $(P=0.006 ; r$ $=0.413)$ and EDEQ-S $(P=0.03 ; r=0.332)$. In the AN group $(\mathrm{n}=27)$, there was a positive correlation between serum glutamate and the scores on EDEQ-W $(P=0.048$; $r$ $=0.399)$.

\section{Regression analysis}

To investigate the relative importance of measured variables as predictors of eating-related psychopathology, multiple regression analyses of selected variables (serum D-serine, serum L-serine, serum glycine, serum glutamine, serum glutamate and glutamate/glutamine ratio) were carried out on WCST, EDEQ, HADS anxiety and HADS depression scores. Stepwise regression analysis indicated that serum glutamate levels in the AN group predicted EDEQ-W scores. In the total sample, stepwise regression analyses also indicated that serum glutamine levels predicted anxiety and depression. When glutamine

Table 2: Post hoc Bonferroni tests for the serum glutamine concentrations

\begin{tabular}{llll}
\hline Group & & $95 \%$ Cl & P value \\
\hline AN $(n=27)$ & $H C(n=28)$ & 61.2 to 353.4 & $0.003^{*}$ \\
& ANRec $(n=18)$ & -13.6 to 316 & 0.083 \\
$H C(n=28)$ & ANRec $(n=18)$ & -219.7 to 107.5 & 1.000 \\
\hline
\end{tabular}

One-way ANOVA, Post hoc Bonferroni test.

*P $<0.05$.

$\mathrm{AN}=$ anorexia nervosa; $\mathrm{ANOVA}=$ analysis of variance; $\mathrm{ANRec}=$ recovered from anorexia nervosa; $\mathrm{HC}=$ healthy controls. 

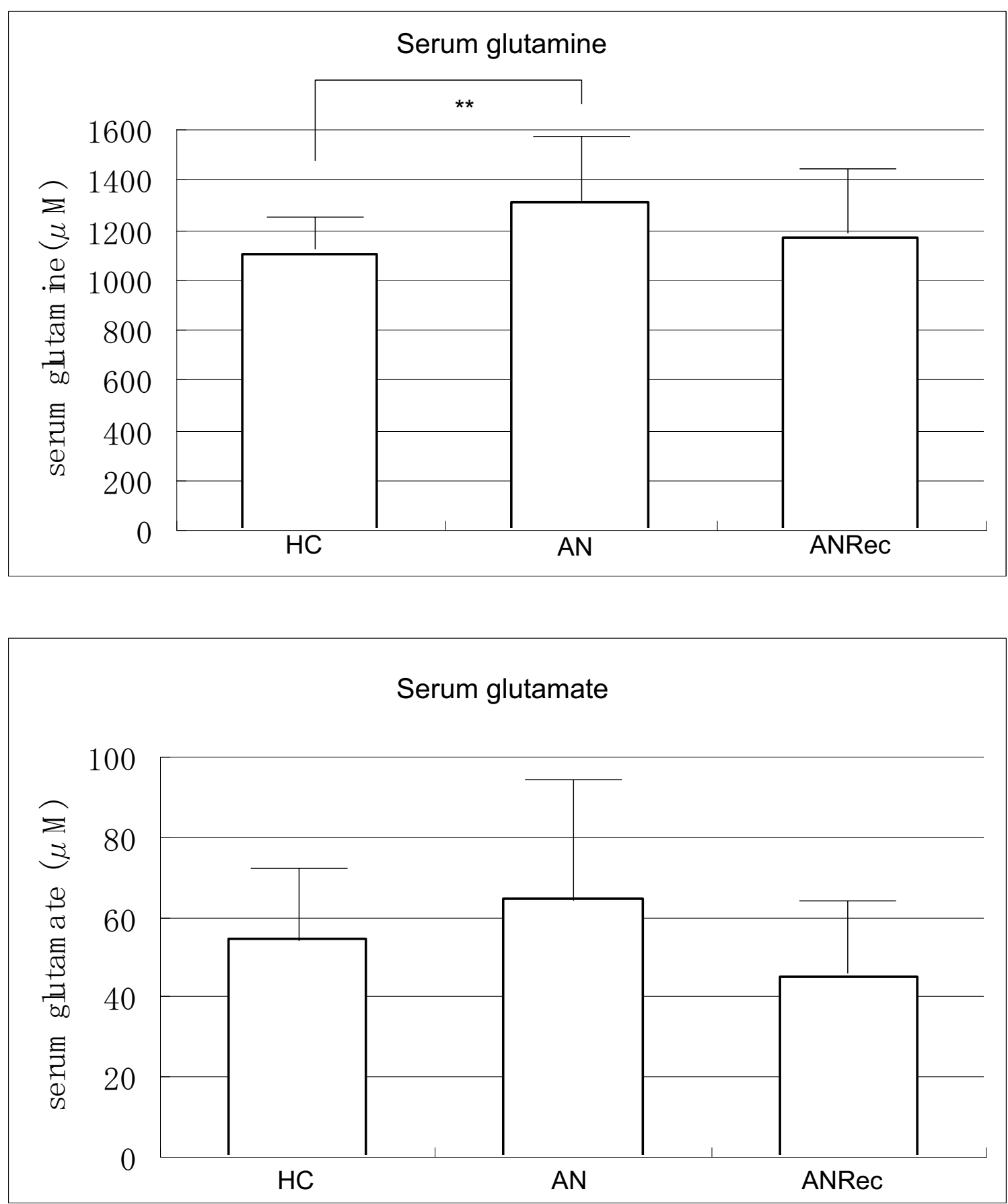

Figure 1 Comparison of serum glutamine concentrations and serum glutamate concentrations in the healthy controls (HC), the patients with anorexia nervosa (AN) and those recovered from AN (ANRec). Values are mean \pm SD; ${ }^{* *} P<0.01$.

was eliminated from this regression model, $18.8 \%$ of the variance that predicted anxiety scores was explained $\left(\mathrm{R}^{2}=\right.$ $0.188, P=0.012,95 \%$ CI -13.1 to $2.7, \beta=0.434$ ) along with $21.4 \%$ of the variance that predicted depression scores $\left(\mathrm{R}^{2}\right.$ $=0.214, \beta=0.462, P=0.007)$. In the AN group, one com- ponent, serum glutamate was extracted and found to explain $90.8 \%$ of the predictive variance of EDEQ-W scores $\left(R^{2}=0.908, P=0.047,95 \% C I-2.14\right.$ to $4.431, \beta=$ 0.953). No other variables were found to predict ED clinical components or set-shifting performance. 
Table 3: Neuropsychological findings of set shifting (performance on the WCST and the Trail Making Task (TMT))

\begin{tabular}{llll}
\hline & AN $(\mathbf{n}=\mathbf{2 4})$ & ANRec $(\mathbf{n}=\mathbf{1 8})$ & HC $(\mathbf{n}=\mathbf{2 8})$ \\
\hline Trail shifting time & $33.3 \pm 17.6$ & $29.6 \pm 11.3$ & $29.1 \pm 8.6$ \\
Trail shifting errors & $2.0 \pm 6.5$ & $0.6 \pm 1.0$ & $0.4 \pm 0.6$ \\
WCST total errors, \% & $24.0 \pm 15.6^{\mathrm{a} * *}$ & $17.6 \pm 8.5$ & $14.9 \pm 7.7$ \\
WCST perseverative errors, $\%$ & $13.0 \pm 10.4^{\mathrm{a} * *}$ & $8.7 \pm 3.5$ & $7.6 \pm 3.4$ \\
\hline
\end{tabular}

Values are mean $\pm \mathrm{SD} ;{ }^{*} P<0.05 ;{ }^{*} P<0.001$.

aComparisons between AN and $\mathrm{HC}$; ${ }^{b}$ comparisons between AN and ANRec; ${ }^{c}$ comparisons between ANRec and $\mathrm{HC}$.

$\mathrm{AN}=$ anorexia nervosa; $\mathrm{ANRec}=$ recovered from anorexia nervosa; $\mathrm{HC}=$ healthy controls; $\mathrm{WCST}=$ the Wisconsin Card Sorting Test.

\section{Discussion}

In this study, we found that serum glutamine concentrations in women currently ill with AN were significantly higher than in a healthy control group of women. The effect size for the mean differences in serum glutamine was 0.87 , which is a large effect size. The effect sizes were 0.36 for serum glutamate, 0.56 for serum glycine, 0.44 for D-serine, 0.31 for L-serine: these are between a small and a medium size. Secondly, our data shows that elevated concentrations of serum glutamine are associated with illness severity. For example, serum glutamine concentrations were negatively correlated with BMI and lowest BMI, and there was a positive correlation between the serum glutamine concentration and duration of illness, and also the EDEQ score. As elevated serum glutamine concentrations are likely to be derived from muscle breakdown and gluconeogenesis during starvation, it is suggested that increased serum glutamine is a state marker for the physiological severity of the AN. Our second hypothesis, namely that serum glutamine concentrations would be related to impairment of set-shifting abilities in people with AN was not confirmed.

Depression has a lifetime prevalence of $5 \%$ to $10 \%$ of young women and has a high comorbidity with AN. Previous studies found that plasma levels of glutamine, glutamate were significantly increased in female patients with depression [33,34]. Given that depression may reflect disturbances in glutamatergic activity, screening $\mathrm{HC}$ controls on psychiatric history might bias the results and that the screening for exclusion should have been based on history of ED only.

In this study, there were no significant differences in the levels of the glutamine/glutamate ratio between the AN and the HC group (Table 1). The amino acid glutamine is involved in glutamate uptake, and although this study was not designed as a turnover study, we hypothesised that we would be able to recognise an altered glutamatergic cycle in patients with AN. The levels of serum glutamine in the AN group were found to be higher than those in the $\mathrm{HC}$ group. One possibility is that in severe AN, raised serum glutamine is a compensatory metabolic response for having decreased levels in the brain due to malnutrition.

The main endogenous source of circulating glutamine is de novo synthesis in striated muscle via the enzyme glutamine synthetase (GS). In animal studies, GS plays a key role in mounting the adaptive response to fasting by transiently facilitating the production of glutamine [35]. Intracellular concentrations of amino acids in the skeletal muscle of healthy non-obese people decrease markedly during fasting; after 3 days of fasting the glutamine concentrations are seen to have fallen [36]. The previous report showed that in $\mathrm{AN}$, reduced body protein could be confirmed by measurement of the triceps skinfold thickness [37]. Taken together, elevated serum glutamine appears to be derived from muscle breakdown and gluconeogenesis during starvation, which in turn is related to BMI and duration of illness. Our second hypothesis that serum glutamatergic amino acids would be related to cognitive impairment of set-shifting abilities in people with AN was not confirmed.

In this study, the AN group showed significantly impaired set-shifting in the WCST, both total errors and perseverative errors. The scores in the recovered group were inbetween those of participants in the acute phase of the illness and HC. Neuropsychological function using WCST was worse in AN participants in comparison with the control group, which was similar to the findings of previous studies [1-5,38].

The limitations of this study were a small sample size and a cross-sectional design. Thus we could not conclude whether serum glutamatergic neurotransmission were associated with set-shifting difficulties both in acute AN and ANRec. A longitudinal study is required, using a larger sample size and exploring other central coherence tasks, in order to clarify whether glutamatergic amino acids are a biological markers for certain endophenotypes of AN.

Finally, it is unclear whether serum glutamatergic concentrations in humans accurately reflect levels in the brain. Such concentrations might represent breakdown of muscle in the periphery, as products of gluconeogenesis, 
rather than reflect changing levels in the brain. Further studies are required to confirm what alterations in glutamatergic neurotransmission occur in the brain of individuals with AN, and how it relates to the pathophysiology. This could be performed using MRS to directly assess the levels of glutamine in the frontal grey matter.

\section{Conclusions}

Elevated serum glutamine may be related to the pathophysiology of AN but does not appear to be linked to functional changes in executive function. Further longitudinal studies are required to explore the associations between glutamatergic amino acid metabolism and cognitive flexibility in AN.

\section{Competing interests}

The authors declare that they have no competing interests.

\section{Authors' contributions}

MN wrote the protocol and carried out the recruitment of the participants, performed the statistical analyses. $\mathrm{KH}$ participated in the design and carried out assay of glutamatergic amino acids. US participated in the design, coordination of the study. KT participated in coordination of the neuropsychological assessment. ICC participated in the design, the interpretation of data, revised the manuscript draft. DAC participated in the design, the management of blood samples. MI participated in the design of the study. JT participated in its design and coordination of the study. All authors participated in the interpretation of data, revised it critically for important intellectual content and have read and approved the final manuscript.

\section{Acknowledgements}

We thank our participants for giving their time to take part in this project.

\section{Author Details}

1Section of Eating Disorders, Institute of Psychiatry, King's College London, UK, 2Department of Child Psychiatry, Chiba University Hospital, Chiba, Japan, ${ }^{3}$ Division of Clinical Neuroscience, Chiba University Center for Forensic Mental Health, Chiba, Japan, ${ }^{4}$ Division of Psychological Medicine and Social Genetic and Developmental Psychiatry Centre, Institute of Psychiatry, King's College London, UK, 5Department of Psychiatry, Chiba University Graduate School of Medicine, Chiba, Japan and ${ }^{6}$ Division of Psychological Medicine, Eating Disorders Research Unit, Department of Academic Psychiatry, King's College, Guy's Hospital, London, UK

Received: 24 February 2010 Accepted: 25 June 2010

Published: 25 June 2010

\section{References}

1. Roberts M, Tchanturia K, Stahl D, Southgate L, Treasure J: A systematic review and meta-analysis of set-shifting ability in eating disorders. Psychosom Med 2007, 37:1075-1084

2. Lopez C, Tchanturia K, Stahl D, Treasure J: Weak central coherence in eating disorders: a step towards looking for an endophenotype of eating disorders. J Clin Exp Neuropsychol 2009, 31:117-125.

3. Tchanturia K, Morris R, Anderluh B, Collier D, Nikolaou V, Treasure J: Set shifting in anorexia nervosa: an examination before and after weight gain, in full recovery and relationship to childhood and adult OCPD traits. J Psychiatr Res 2004, 38:545-552.

4. Tchanturia K, Campbell I, Morris R, Treasure J: Neuropsychological studies in anorexia nervosa. Int J Eat Disord 2005, 37(Suppl):72-76.

5. Holliday J, Tchanturia K, Landau S, Collier D, Treasure J: Is impaired setshifting an endophenotype of anorexia nervosa? Am J Psychiatry 2005, 162:2269-2275.

6. Wobrock T, Ecker UK, Scherk H, Schneider-Axmann T, Falkai P, Gruber O: Cognitive impairment of executive function as a core symptom of schizophrenia. World J Biol Psychiatry 2009, 10:442-451.
7. Sachs G, Schaffer M, Winklbaur B: Cognitive deficits in bipolar disorder. Neuropsychiatr 2007, 21:93-101.

8. Rao NP, Reddy YC, Kumar KJ, Kandavel T, Chandrashekar CR: Are neuropsychological deficits trait markers in OCD? Prog Neuropsychopharmacol Biol Psychiatry 2008, 32:1574-1579.

9. Snitz BE, Macdonald AW, Carter CS: Cognitive deficits in unaffected firstdegree relatives of schizophrenia patients: a meta-analytic review of putative endophenotypes. Schizophr Bull 2006, 32:179-194.

10. Bora $\mathrm{E}$, Yucel M, Pantelis C: Cognitive endophenotypes of bipolar disorder: a meta-analysis of neuropsychological deficits in euthymic patients and their first-degree relatives. J Affect Disord 2009, 113:1-20.

11. Jamain S, Betancur C, Quach H, Philippe A, Fellous M, Giros B, Gillberg C, Leboyer M, Bourgeron T, Paris utism Research International Sibpair (PARIS) Study: Linkage and association of the glutamate receptor 6 gene with autism. Mol Psychiatry 2002, 7:302-310.

12. McGale EH, Pye IF, Stonier C, Hutchinson EC, Aber GM: Studies of the inter-relationship between cerebrospinal fluid and plasma amino acid concentrations in normal individuals. J Neurochem 1977, 29:291-297.

13. Alfredsson G, Wiesel FA, Tylec A: Relationships between glutamate and monoamine metabolites in cerebrospinal fluid and serum in healthy volunteers. Biol Psychiatry 1988, 23:689-97.

14. Castro-Fornieles J, Bargalló N, Lázaro L, Andrés S, Falcon C, Plana MT, Junqué C: Adolescent anorexia nervosa: cross-sectional and follow-up frontal gray matter disturbances detected with proton magnetic resonance spectroscopy. J Psychiatr Res 2007, 41:952-958.

15. Ohrmann P, Kersting A, Suslow T, Lalee-Mentzel J, Donges US, Fiebich M, Arolt $V$, Heindel W, Pfleiderer B: Proton magnetic resonance spectroscopy in anorexia nervosa: correlations with cognition. Neuroreport 2004, 15:549-553.

16. Nicolle MM, Baxter MG: Glutamate receptor binding in the frontal cortex and dorsal striatum of aged rats with impaired attentional setshifting. Eur J Neurosci 2003, 18:3335-3342.

17. Goff D, Coyle J: The emerging role of glutamate in the pathophysiology and treatment of schizophrenia. Am J Psychiatry 2001, 158:1367-1377.

18. Hashimoto K, Fukushima T, Shimizu E, Komatsu N, Watanabe H, Shinoda N, Nakazato M, Kumakiri C, Okada S, Hasegawa H, Imai K, Iyo M: Decreased serum levels of D-serine in patients with schizophrenia: evidence in support of the N-methyl-D-aspartate receptor hypofunction hypothesis of schizophrenia. Arch Gen Psychiatry 2003, 60:572-576

19. Roberts AC, Robbins TW, Everitt BJ, Muir JL: A specific form of cognitive rigidity following excitotoxic lesions of the basal forebrain in marmosets. Neuroscience 1992, 47:251-264.

20. Stefani MR, Groth K, Moghaddam B: Glutamate receptors in the rat medial prefrontal cortex regulate set-shifting ability. Behav NeurosC 2003, 117:728-737.

21. Darrah JM, Stefani MR, Moghaddam B: Interaction of $N$-methyl-Daspartate and group 5 metabotropic glutamate receptors on behavioral flexibility using a novel operant set-shift paradigm. Behav Pharmacol 2008, 19:225-234.

22. Roser W, Bubl R, Buergin D, Seelig J, Radue EW, Rost B: Metabolic changes in the brain of patients with anorexia and bulimia nervosa as detected by proton magnetic resonance spectroscopy. Int J Eat Disord 1999 26:119-136

23. Schlemmer HP, Möckel R, Marcus A, Hentschel F, Göpel C, Becker G, Köpke J, Gückel F, Schmidt MH, Georgi M: Proton magnetic resonance spectroscopy in acute, juvenile anorexia nervosa. Psychiatry Res 1998 82:171-179.

24. American Psychiatric Association: Diagnostic and Statistical Manual of Mental Disorders 4th edition. Washington DC: American Psychiatric Press; 1994

25. Fairburn C, Beglin S: Assessment of eating disorders: interview or selfreport questionnaire? Int J Eat Disord 1994, 16:363-370.

26. Hodgson R, Rachman S: Obsessional-compulsive complains. Behav Res Ther 1977, 15:389-395.

27. Zigmond A, Snaith R: The hospital anxiety and depression scale. Acta Psychiatr Scand 1983, 67:361-370.

28. Hashimoto K, Engberg G, Shimizu E, Nordin C, Lindström L, lyo M: Elevated glutamine/glutamate ratio in cerebrospinal fluid of first episode and drug naive schizophrenic patients. BMC Psychiatry 2005, $31: 6$. 
29. Yamada $K$, Ohnishi T, Hashimoto K, Ohba H, Iwayama-Shigeno $Y$ Toyoshima M, Okuno A, Takao H, Toyota T, Minabe Y, Nakamura K, Shimizu E, Itokawa M, Mori N, Iyo M, Yoshikawa T: Identification of multiple serine racemase (SRR) mRNA isoforms and genetic analyses of SRR and DAO in schizophrenia and D-serine levels. Biol Psychiatry 2005, 57:1493-1503.

30. Fukushima T, Kawai J, Imai K, Toyo'oka T: Simultaneous determination of D- and L-serine in rat brain microdialysis sample using a columnswitching HPLC with fluorimetric detection. Biomed Chromatogr 2004, 18:813-819.

31. Heaton RK, Chelune GJ, Talley JL, Kay G, Curtiss G: Wisconsin Card Sorting Test. Computer version 4th edition. Edited by: Odessa FL. Psychological Assessment Resources; 1993.

32. Reitan RM: The relation of the trail making test to organic brain damage. J Consult Psychol 1955, 19:393-394.

33. Küçükibrahimoğlu E, Saygin MZ, Calişkan M, Kaplan OK, Unsal C, Gören $M Z$ : The change in plasma GABA, glutamine and glutamate levels in fluoxetine- or S-citalopram-treated female patients with major depression. Eur J Clin Pharmacol 2009, 65:571-577.

34. Mitani H, Shirayama Y, Yamada T, Maeda K, Ashby CR Jr, Kawahara R: Correlation between plasma levels of glutamate, alanine and serine with severity of depression. Prog Neuropsychopharmacol Biol Psychiatry 2006, 30:1155-1158.

35. Kravariti E, Morris RG, Rabe-Hesketh S, Murray RM, Frangou S: The Maudsley Early Onset Schizophrenia Study: cognitive function in adolescent-onset schizophrenia. Schizophr Res 2003, 65:95-103.

36. He Y, Hakvoort TB, Koehler SE, Vermeulen JL, de Waart DR, de Theije C, Ten Have GA, van Eijk HM, Kunne C, Labruyere WT, Houten SM, Sokolovic M, Ruijter JM, Deutz NE, Lamers WH: Glutamine synthetase in muscle is required for glutamine production during fasting and extrahepatic ammonia detoxification. J Biol Chem 2010, 285:9516-9524.

37. Kerruish KP, O'Connor J, Humphries IR, Kohn MR, Clarke SD, Briody JN Thomson EJ, Wright KA, Gaskin KJ, Baur LA: Body composition in adolescents with anorexia nervosa. Am J Clin Nutr 2002, 75:31-37.

38. Zastrow A, Kaiser S, Stippich C, Walther S, Herzog W, Tchanturia K, Belger A, Weisbrod M, Treasure J, Friederich HC: Neural correlates of impaired cognitive-behavioral flexibility in anorexia nervosa. Am J Psychiatry 2009, 166:608-616.

doi: 10.1186/1744-859X-9-29

Cite this article as: Nakazato et al., Serum glutamine, set-shifting ability and anorexia nervosa Annals of General Psychiatry 2010, 9:29

Submit your next manuscript to BioMed Centra and take full advantage of:

- Convenient online submission

- Thorough peer review

- No space constraints or color figure charges

- Immediate publication on acceptance

- Inclusion in PubMed, CAS, Scopus and Google Scholar

- Research which is freely available for redistribution

Submit your manuscript at www.biomedcentral.com/submit
C Biomed Central 